\title{
The Nicoya region of Costa Rica: a high longevity island for elderly males
}

\author{
Luis Rosero-Bixby, William H. Dow and David H. Rehkopf*
}

\begin{abstract}
Reliable data show that the Nicoyan region of Costa Rica is a hot spot of high longevity. A survival follow-up of 16,300 elderly Costa Ricans estimated a Nicoya death rate ratio (DRR) for males 1990-2011 of 0.80 (0.69-0.93 CI). For a 60-yearold Nicoyan male, the probability of becoming centenarian is seven times that of a Japanese male, and his life expectancy is 2.2 years greater. This Nicoya advantage does not occur in females, is independent of socio-economic conditions, disappears in out-migrants and comes from lower cardiovascular $(\mathrm{CV})$ mortality $(\mathrm{DRR}=0.65)$. Nicoyans have lower levels of biomarkers of CV risk; they are also leaner, taller and suffer fewer disabilities. Two markers of ageing and stress-telomere length and dehydroepiandrosterone sulphate-are also more favourable. The Nicoya diet is prosaic and abundant in traditional foods like rice, beans and animal protein, with low glycemic index and high fibre content.
\end{abstract}

\section{Introduction}

A book published by the National Geographic Society identified the region of Nicoya in Costa Rica as one of a very small number of locations in the world with exceptional longevity-regions that were referred to as blue zones (Buettner 2010). Other locations noted as having high longevity were the islands of Sardinia in Italy and Okinawa in Japan. Although the selection of Nicoya was mostly based on unpublished evidence, more than a century earlier a Swiss geographer and botanist had observed: "in no other place people are blessed with such long lives" (Pittier 1904). Recently, this high longevity has been examined in a population-based sample of elderly Costa Ricans, finding that Nicoya indeed has a significantly lower death rate ratio of 0.71 compared to the rest of the country (Rosero-Bixby and Dow 2012),

\footnotetext{
${ }^{*}$ Luis Rosero-Bixby (correspondence author), UCB Department of Demography, USA.

Email: Lrosero@mac.com

William H. Dow, University of California, USA.

David H. Rehkopf, Stanford University, USA.
} 
which is an extraordinary result given the already high life expectancy of elderly Costa Ricans in general (Rosero-Bixby 2008).

This article helps fill the gap of scientific evidence regarding life expectancy and health among elderly Nicoyans by: (1) better quantifying their survival advantage, if any; and (2) singling out biomarkers, diet consumption patterns and other health indicators in which Nicoyans are different from all other elderly Costa Ricans. Thus the questions that this article will seek to address are whether Nicoya is truly an island of longevity; what the extent is of this longevity advantage in terms of relative mortality, life expectancy and survival probabilities; and finally, in what aspects of health elderly Nicoyans are different from those living in the rest of Costa Rica.

A key scientific rationale for looking after hot spots of longevity is the identification of clues to healthy or successful ageing (Willcox et al. 2008). However, this quest for longevity islands has proved to be problematic. Claims of exceptional longevity in little-developed communities in the Andes and in the Caucasus (Leaf and Launois 1975) did not stand up to systematic scrutiny of the true age of supposed centenarians or supercentenarians (Garson 1991) (Young et al. 2010). Demographers are also aware that age exaggeration among the oldest old in censuses leads to substantial age inflation in very old-age populations, and consequently, to underestimated mortality rates at old ages when computed using census-based denominators especially in populations with low levels of literacy (Coale and Kisker 1986; Preston et al. 1999). In part motivated by these prior instances of biased data, recent studies have been especially careful about using only reliable and well-documented information on the age of elderly people, such as those conducted in Okinawa (Willcox et al. 2008; Poulain 2011) and Sardinia (Caselli and Lipsi 2006). The current study described here similarly uses only well-documented information on birth dates from the civil registration system that has existed in Costa Rica since 1883, instead of self-reported ages.

Costa Rica, the context for this study, is known as a country with outstanding health indicators in spite of its limited level of economic development. It was included, for example, as one of the four study cases in the Rockefeller Foundation report on 'Good Health at Low Cost' (Halstead et al. 1985). The 4.5 million Costa Ricans have the second-highest life expectancy in the Americas (Canada has the highest), higher than wealthier countries like the United States, Chile, or Brazil. Its public health insurance system is almost universal, and its network of primary healthcare providers is believed to have helped improve the health of disadvantaged groups and led to only small socio-economic gradients in health (Rosero-Bixby and Dow 2009). Elderly Costa Ricans, particularly males, have been singled out as one of the national populations whose mortality is among the lowest in the world (Rosero-Bixby 2008). According to the United Nations, age 60 life expectancy among Costa Rican males is 22.0 years in 2010-2015, higher than in western Europe (21.9 years on average) or than the 21.5 years of the United States (UN Population Division 2012). This is outstanding for a middle-income country whose health expenditure per capita is one-tenth of that in the United States (World Bank 2012). The research presented 
here further expands on the details of Costa Rica's noteworthy longevity to focus on the Costa Rican region of Nicoya.

The Nicoya Peninsula is located in the northeast of Costa Rica bordering the Pacific Ocean (map in Figure 1). For the purposes of this article the Nicoya region comprises the following five neighbouring cantons: Santa Cruz, Carrillo, Nicoya, Nandayure and Hojancha. Its population is 161,000 , with $47 \%$ residing in urban areas, mostly in three small cities of about 25,000 inhabitants: Nicoya, Santa Cruz and Filadelfia according to the 2011 census. Eight percent of this population is aged 65 years or more and the number of centenarians counted in that census was 32. Nicoya's indicators of development are slightly below national averages. For example, the 2011 census shows that $35 \%$ of adults have completed high school (37\% national) and 30\% of households own a car (38\% national). Although in Costa Rica indigenous peoples are of little quantitative importance ( $2 \%$ according to the 2011 census), in Nicoya the indigenous population is higher: 5\% reported being of the Chorotega ethnic group. Most of the Nicoya population is located inland, partly in a hilly area with altitudes between 100 and 500 metres. According to Holdridge's classification, Nicoya is a tropical life-zone mostly covered by dry to moist forests and pastures (Tosi 1969). In the dry season that goes from December to April the historical rainfall is almost null: $60 \mathrm{~mm}$ in five months (IMN 2012). In the rainy season, from May to November, there is abundant precipitation for a total of $1,700 \mathrm{~mm}$ rainfall. Temperatures are warm all year: minimum $22^{\circ} \mathrm{C}$ in January and maximum $36^{\circ} \mathrm{C}$ in April.

\section{Data and methods}

This article comprises three different analyses and datasets described below.

(1) Spatial mortality analysis of quasi-extinct cohorts born before 1920 to determine clusters of significantly lower elderly mortality in Costa Rica 1990-2011. The database for the analysis included about 78,000 death records from 1990-2011 plus about 2,000 individuals alive in December 2011 according to the voting registry. These data do not include approximately 7,500 non-native Costa Ricans and individuals who had been registered late in life because the birth registration was somehow missing. The geographic coordinates of each individual were those of the voting precinct in which the individual was registered to vote in the 1990 presidential election. There were 1,709 of these precincts in the 1990 election, with a mean number per precinct of 41 individuals born before 1920 (range 1 to 1,470).

We used the 'Satscan' procedure and its corresponding software to identify clusters of communities with lower than expected elderly mortality. Satscan was developed to help epidemiologists to detect spatial clusters of a disease (Kulldorff 1997). In short, for all possible circles around each of the data points, it computes relative risk by comparing the number of 'cases' to its 'expected value' given the circle's exposure level assuming a Poisson distribution. Satscan uses the log-likelihod ratio-estimated 
using Monte Carlo simulation-to rank clusters, to identify the most likely cluster as well as secondary clusters, and to determine their statistical significance. In our computations we adjusted 'expected values' of dying by age, sex and time, assuming that expected mortality follows a baseline Gompertz function estimated with the national data for these cohorts. We fixed a maximum radius at $6 \%$ of the population to do the spatial scan. One particular strength of this approach is that it is completely data-driven and thus not influenced by any investigator bias in drawing borders around alleged clusters, nor is it susceptible to multiple testing that seeks to confirm prior hypotheses. The Satscan method is generally considered to be conservative for identifying clusters, and often results in finding no significant clusters (Thomas and Carlin 2003).

(2) Longitudinal mortality follow-up of probabilistic samples from the 1984 and 2000 national censuses to determine the mortality of Costa Ricans aged 60 years or more in the period 1990-2011 with a focus on the relative death rate of residents, immigrants and out-migrants of the Nicoya region. The sample from the 1984 census was part of the Costa Rican Longitudinal Mortality Study (CR-LMS) described elsewhere (Rosero-Bixby and Antich 2010). Only individuals aged 60 and over during the period 1990-2000 $(N=8,700)$ were taken from the CR-LMS database which originally included ages 30 years and over. The observation period starts in 1990 (instead of 1984) for two reasons: (1) the first available voting registry is the one for the 1990 elections, and the follow-up method required verifying survival by linking the census data to the voting lists; and (2) to ensure that all individuals in the sample were born after the national birth registry was established in 1883 and thus are younger than 107 years in 1990. We start observation at age 60 (for example an individual born in 1935 enters into observation in 1995 when he or she reaches the age 60) to study mortality in 1990-2000 in the same age range as in the period 2001-2011 with the second sample. We censored follow-up in December 2000 to reduce the possibility that certain characteristics recorded in the 1984 census, such as residence in Nicoya or insurance status, were no longer valid.

The sample from the 2000 census $(N=7,600)$ was part of the Costa Rican Study of Longevity and Healthy Ageing (CRELES, Spanish language acronym) described elsewhere (Rosero-Bixby and Dow 2009). The observation period started six months after the census date (June 2000) to reduce the bias of individuals close to death who might not be included in the census count.

The two samples pooled together in a survival time dataset included more than sixteen thousand individuals observed during 123,000 years, with close to six thousand deaths (Table 1). About $6 \%$ of this population is of Nicoya residents. Although most of the observation ages are of individuals younger than 75 years, there is still reasonable sampling size for quasi-centenarians $-4,500$ person years, 500 of them from people in Nicoya-because of over-sampling of older ages. The geographic and socio-economic characteristics of individuals come from the 1984 census for 1990-2000 and from the 2000 census for 2001-2011. Ages were computed from the DOB in the Birth Registry and deaths were identified by computer follow-up 
Table 1:

The elderly mortality follow-up sample

\begin{tabular}{lrrr}
\hline Variable & Non-Nicoya & Nicoya & Costa Rica \\
\hline No. of individuals & 15,389 & 926 & 16,315 \\
Deaths & 5,323 & 366 & 5,689 \\
Person-years (thousands) & & & \\
Total & 116.6 & 6.7 & 123.2 \\
Age 60-74 & 70.9 & 3.5 & 74.4 \\
Age 75-94 & 41.7 & 2.6 & 44.3 \\
Age 95+ & 3.9 & 0.5 & 4.5 \\
Mean age (years) & 73.1 & 75.6 & 73.3 \\
Mean calendar year & 2000 & 2000 & 2000 \\
Mean years of education & 4.4 & 3.2 & 4.3 \\
Health insurance: & & & \\
$\quad$ None & $15 \%$ & $17 \%$ & $15 \%$ \\
$\quad$ Government-paid & $14 \%$ & $25 \%$ & $14 \%$ \\
\hline
\end{tabular}

Note: Means and percentages were computed with person-years.

in the Death Registry until 30 November 2011. Only individuals who appear in the voting lists for the presidential elections (every four years) from 1990 to 2010 were included in the analysis. The database was set as survival-time, with the 60th birthday as origin, entry time on 1 January 1990 or 2001, depending on the source sample, and censoring on 31 December 2000 for the first sample or 30 November 2011 for the second sample. For a group of $431(2.6 \%)$ missing individuals from voting lists, we randomly assigned a censoring date sometime during the period of four years before the date of the first voting list in which he or she is missing.

We used proportional hazard regression models (Hosmer and Lemeshow 1999) to estimate smoothed death rates in this sample as well as the Nicoya effect, including an assessment of the effect of migration from, and to, Nicoya using census information on place of birth. We estimated parametric hazard regression models assuming a Gompertz distribution, which is known to be a good description of human mortality at adult ages (Missov and Lenart 2011) and controlled for age, sex and time-trend. From the estimated Gompertz function we computed three summary indicators for individuals at their 60th birthday: the median lifetime, the probability of reaching 100 years of age and the life expectancy for a 60 -year old, the latter by numerical integration of the survival function.

In addition to the analysis of all-cause mortality we estimated hazard regression models for two large groups of causes of death: cancer (codes C01 to D48 in ICD-10, the 10th revision of the International Classification of Diseases) and cardiovascular diseases (codes I01 to I99). Deaths by other causes were taken as censored observations on the death date. In spite of its large sample size, this dataset has limited statistical power for conducting analyses by cause of death. The power 
for detecting Nicoya effects on all-cause mortality in proportional hazard models stratified by sex is 0.79 for a hazard ratio (HR) of 0.8 (i.e. $20 \%$ lower mortality in Nicoya). ${ }^{1}$ For cardiovascular mortality, which includes about one-third of all deaths, the power to detect HR of 0.8 is only 0.37 , so one must look at HR of 0.7 to have a more palatable power of 0.74 . The statistical power of this sample is even lower for studying cancer deaths, the second largest group of causes of death, and it is insufficient for studying death rates by causes of death that occur in substantially smaller numbers than cancer or cardiovascular deaths.

A confirmatory cohort analysis of the relative survival ratios of Nicoya was conducted with data from the 1984, 2000 and 2011 censuses. In this analysis the information on age is from self-report in the censuses and thus it can suffer from age exaggeration errors. However, such errors may affect our conclusions only if they are different in Nicoya than in the rest of the country.

(3) Cross-sectional comparison of biomarkers, diet and other health risk factors from the in-depth CRELES study. This is a longitudinal study based on a national sample of residents of Costa Rica aged 60 and older in 2005, with oversampling of the oldest old (Rosero-Bixby et al. 2010). The survey was conducted in a subsample of nearly 3,000 individuals, including 350 from Nicoya, drawn from the sample used in the aforementioned mortality analysis. Individuals were visited three times at intervals of about two years for household interviews to collect information about health, socio-economic status, lifestyles and life course events mostly in the period 2005-2009. The survey included physical examinations (for example, blood pressure, anthropometry, performance and mental tests) as well as the collection of urine and fasting blood. Nicoya differences were estimated for nine groups of 18 biomarkers:

1. Metabolic indicators: Fasting glucose; glycosylated hemoglobin (HbA1c).

2. Cardiovascular: Diastolic blood pressure (BP); systolic BP.

3. Lipids: Triglycerides; total/HDL cholesterol ratio.

4. Stress: urine cortisol; dehydroepiandrosterone sulphate (DHEAS); leukocyte telomere length.

5. Inflammation: C-reactive protein (CRP).

6. Organ-specific function reserve: serum creatinine; handgrip strength.

7. Nutrition: Knee height; body-mass index (BMI); waist circumference.

8. Functionality: Activities of daily life (ADL) disability scale based on 14 items.

9. Mental health: cognitive mini-mental score; Yesavage geriatric depression test.

This analysis used information from the first and second CRELES waves, since the third wave did not collected biological specimens. Sample sizes for most biomarkers are about 5,000 observations, including 600 for Nicoya. Exceptions are leukocyte telomere length, which was measured in just a subsample of about 1,000 observations,

\footnotetext{
1 These power estimates follow the method proposed by Schoenfeld (1983), assuming a constant hazard ratio of 0.045 annually, over an observation period of 10 years, and a sample size of 8,000 in each sex, 520 from Nicoya.
} 
400 from Nicoya (Rehkopf et al. 2013 forthcoming), cortisol (2,200 observations) measured in the first wave only, and geriatric depression (3,800 observations) that was not measured in about $25 \%$ of the sample requiring a proxy respondent.

Intake of 15 macronutrients was also studied. CRELES estimated nutrient intake from information on frequency of consumption (and portion sizes) of 27 tracer foods as described elsewhere (Rosero-Bixby et al. 2010). Sample size in this analysis was more than 7,000 observations-900 from Nicoya-in the three waves of CRELES.

For comparison purposes, biomarkers and macronutrients where normalised to mean zero and standard deviation of one. We used regression models on the normalised variables of interest (a biomarker or a nutrient) to estimate the 'Nicoya effect' as the regression coefficient of a dummy variable for residence in Nicoya. The effects are measured as the change in standard deviations associated with residence in Nicoya. To control for confounding effects, the regression models included control variables for survey wave, age (continuous single year and squared), sex and interactions between sex and age and Nicoya. Robust estimates of standard errors of the regression coefficients are used to take into account the clustering of observations within the same individual.

The available sample size allows for detection of differences (Nicoya vs. other residence) in the order of 0.2 S.D. or higher with a statistical power of 0.8 or differences of at least 0.25 in sex-stratified analyses. Unfortunately, it does not allow survival analyses of the Nicoya effect with high enough statistical power. Proportional hazard models could detect HR 0.70 (Nicoya/other) with 0.80 statistical power; if stratified by sex, the detectable HR is 0.6 with a 0.77 power.

The values of some key health factors, such as smoking or coverage of health services, are also compared between Nicoya and the rest of the country using the information from the three CRELES waves. The comparison controls confounding effects of age and sex using logistic regressions.

\subsection{Validity of mortality estimates}

Validity of mortality estimates for Costa Rica and Nicoya rest on the accuracy of the information on age and on the complete registration of all deaths in the two longitudinal databases we studied.

Age of the individuals in the three databases of this article did not come from self-reports but was computed from the date of birth (DOB) recorded in the national birth registry, which also appears on the identification card (the cédula). The National Electoral Tribunal (Tribunal Supremo Electoral or TSE) - the institution that since 1949 has been in charge of the civil registration system of births, deaths and naturalisations, as well as of preparing the voting lists-provided the data from these registries. Linking between the different registries was possible using the unique identification number that all Costa Ricans acquire when their birth (or naturalisation) is entered into the corresponding ledgers. This identification is 
a sequential number impossible to tamper with ${ }^{2}$ - unless there is impersonation. Moreover, those individuals registered years after they were born, because of naturalisation or a missing birth record, are identifiable and were excluded from the analyses. Since our two mortality analyses cover the period 1990-2011, all individuals were born after the establishment of the registration system in 1883: the oldest individuals included in the extinct-cohort analysis were: one born in 1886 and another in 1887, and the oldest in the sample for the longitudinal follow-up were three born in 1889. The proportion excluded because of late registration (or naturalisation) in the extinct-cohort analyses were $100 \%$ of eight supposedly born in $1883-85,29 \%$ of 91 born in $1886-90,17 \%$ of 728 born in $1891-95$ and $8 \%$ of the about 80,000 born in 1996-1919. The majority of these exclusions are immigrants. The excluded individuals had significantly lower mortality.

Recent demographic evaluations conclude that the Costa Rican death registration system is essentially free of under-registration errors (INEC and CCP 2013). Since 1961, the United Nations has graded the Costa Rican vital statistics system as "complete" (Nations 1961). The country is also one of eleven developing countries whose vital registration statistics in 1995 were characterised by Hill et al. as both complete (recording at least $90 \%$ of births and deaths) and accurate (producing mortality estimates similar to those based on census and survey data) (Hill et al. 1999). Evidence from the CRELES survey confirms the completeness of registration deaths of elderly people. In a subsample of 566 deaths found independently during household visits in the CRELES survey, only five (less than 1\%) were not found in the death registry (because they may not be registered or were registered with a wrong identification), which gives a reasonable assurance that registration of deaths in Costa Rica is essentially complete.

\footnotetext{
2 The birth ledgers are sequentially numbered within each of the seven Costa Rican provinces, as well as within the pages within each book and the lines within each page. Births are sequentially recorded in about 15 to 20 lines of these pages. The identification number of a Costa Rican includes the province code, the volume, the page and the starting line where their birth (or naturalisation) is entered. It is impossible for somebody born in, say 1930, to have an identification number that corresponds to a ledger of, say 1910. Late registrations are identifiable by comparing the identification number and the date of birth. The system has existed uninterrupted since 1883 and the ledgers are kept in safe vaults at the TSE. Since the early 1970s the registration system has also been filed in computer databases. Costa Ricans were progressively entered into the computer files each time they made contact with the Civil Registry to renew their identification card every ten years, to register a vital event or to obtain a vital certificate.
} 


\section{Results}

\subsection{Spatial analysis}

The spatial analysis of mortality in the quasi-extinct cohorts born before 1920 singled out a dominant cluster of lower-than-expected elderly mortality in the Peninsula of Nicoya as well as a secondary cluster in the area of San Vito, close to the Panama border. The map in Figure 1 shows the two circles of low mortality found with the Satscan procedure. The map also shows the geographic location of the data points included in the Satscan analysis, which are the voting precincts in the 1990 election, with point size proportional to population.

The data points included in the dominant cluster of Nicoya are all in the five cantons of Carrillo, Santa Cruz, Nicoya, Hojancha and part of Nandayure as one moves from North to South. These five cantons define the so-called Blue Zone of Nicoya. The relative mortality rate in this cluster is 0.83 ( 0.80 to 0.86 confidence interval at $95 \%$ ) compared to the national rate in the period 1990-2011 for people born before 1920 , i.e. aged 70 years and over. The secondary cluster includes the town of San Vito and its northern neighbouring areas with a relative mortality rate of 0.66 $(0.55$ to $0.80 \mathrm{CI})$. These are age- and sex-adjusted relative death rates. Although the cluster of San Vito has a substantially lower mortality than Nicoya, it is a secondary cluster because of its smaller population size. ${ }^{3}$ Because of its tiny population size it is of lower interest, and therefore we continue to focus on the Nicoyan cluster for the remainder of this paper.

\subsection{Survival follow-up sample}

To check the validity of the survival follow-up sample, Figure 2 compares the sample age-specific mortality rates (period 1990-2011) with the observed national rates in the period 1995-2005 (CCP 2012b).

No biases in the sample estimates are apparent. The figure also shows that both the sample and population death rates increase in logarithms almost linearly, especially below age 100 years, which makes it appropriate to fit them with a Gompertz function as shown by the thick lines estimated with the sample data. The constant term or intercept (0.0103 for males and 0.0070 for females) of the Gompertz function is actually the death rate at age 60 , which can be taken as an indicator of the general level of mortality. The 'gamma' coefficient is a senescence rate that estimates the

\footnotetext{
3 According to the 2011 census, the total population in the San Vito Cluster (districts of Potrero Grande, Volcán, Limoncito, Pittier, Biolley and Chaguena) is 12,000 (compared to the 161,000 of Nicoya) and the number of centenarians is just 2. As in Nicoya, the San Vito Population resides inland in hilly areas with altitudes ranging from 500 to 1,000 metres above sea level. It has a relatively large proportion of aboriginal people (16\%) of the Guaymí, Bribrí and Teribe ethnic groups. An additional feature of note is that the town of San Vito was founded by Italian settlers.
} 
Figure 1:

Map of location of the quasi-extinct Costa Rican cohorts born before 1920 and the two clusters of significantly lower elderly mortality detected with Satscan

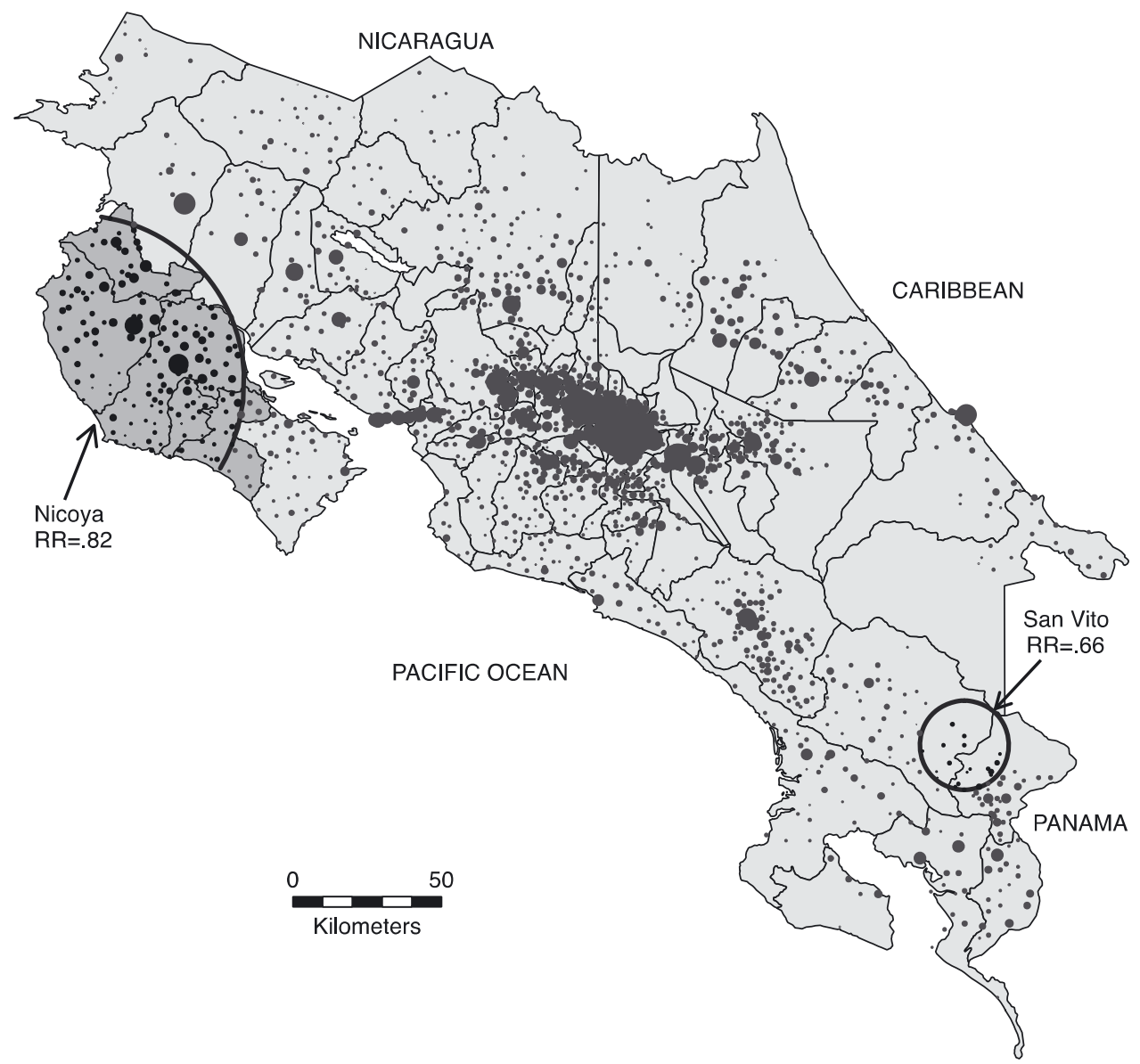

Note: Each point is a voting location. Points are proportional to population size. Canton limits shown.

rate at which mortality increases with each year of age: $8.6 \%$ for males and $9.4 \%$ for females. To provide some perspective, the figure also shows the age-specific death rates in Japan 1995-2005 - a population with one of the lowest recorded mortality levels in the world-from the Human Mortality Database (HMD 2012). Elderly males show similar mortality patterns in Costa Rica and Japan: slightly higher in Costa Rica until about age 80 and slightly higher among the oldest old in Japan. Among females, elderly mortality is clearly higher in Costa Rica than in Japan until age 85 and very similar afterward. 


\section{Figure 2:}

Age-specific mortality rates in the survival follow-up sample and in the entire population of Costa Rica and Japan by sex
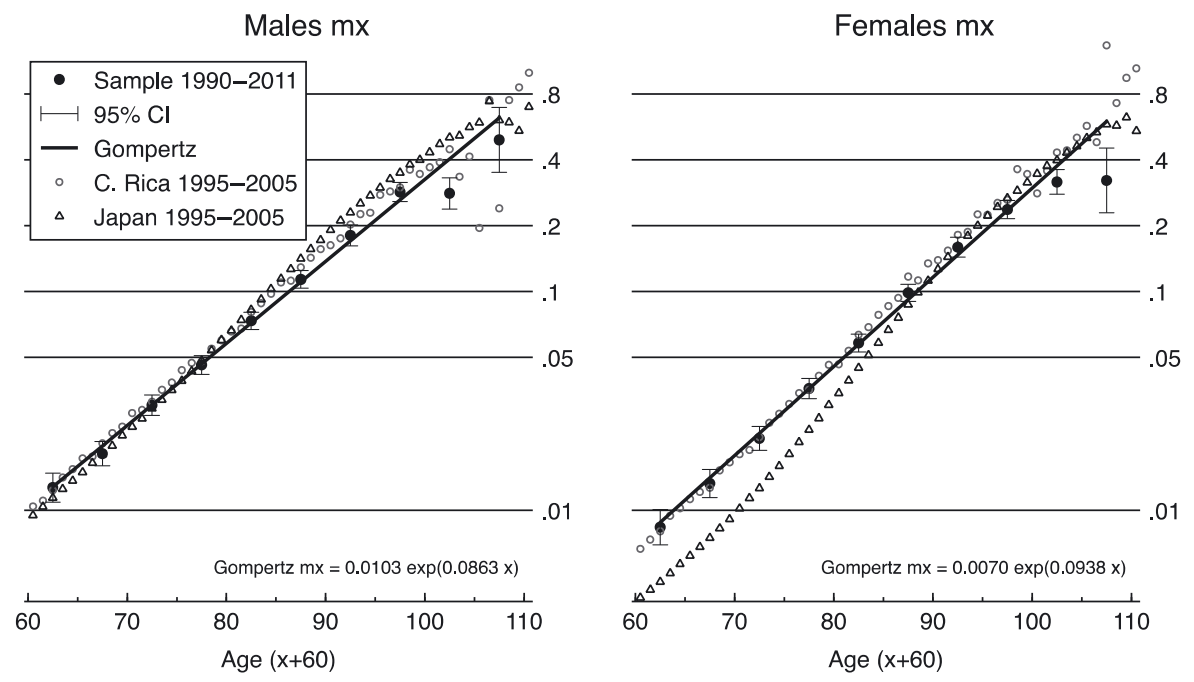

Since preliminary hazard regression results showed that Nicoya effects differ substantially by sex, all mortality analyses were conducted separately for males and females (Table 2). By the same token, since there were no significant interactions of the Nicoya effect with age or calendar time, analyses were not stratified by age groups or sub-periods.

The base model 1 of Table 2 shows that death rate ratios (DRR) of elderly male residents in Nicoya are on average 0.80 (95\% CI: 0.69-0.93) compared to the rest of Costa Rica: i.e. a mortality level that is $20 \%$ lower than the national average. In contrast, the DRR for Nicoyan women is not significantly different from the national one. The Nicoya mortality advantage occurs only among men.

The SES controls model 2 of Table 2 shows that socio-economic characteristics, such as education and access to healthcare, have little to do with the above results. The Nicoya effects estimated with the second regression model in Table 2 are essentially the same as in the base model: $19 \%$ lower mortality for men and non-significant effects for women. As shown in Table 1, elderly Nicoyans have lower levels of education and about the same coverage of health insurance as the rest of elderly Costa Ricans.

We also estimate the Nicoya advantage by lifetime migration status, to explore the question of whether the Nicoya advantage comes from solely genetic factors or from the environment (model 3 of Table 2). Elderly men born and still residing in Nicoya have the lowest DRR of 0.77 (95\% CI: 0.65-0.92). Those born outside Nicoya and currently residing in the Peninsula - the immigrants-have a non-significant DRR 
Table 2:

Nicoya death rate ratio (DRR) estimated with hazard regression models

\begin{tabular}{|c|c|c|c|c|}
\hline \multirow[b]{2}{*}{$\begin{array}{l}\text { Explanatory } \\
\text { variable }\end{array}$} & \multicolumn{2}{|c|}{ Males } & \multicolumn{2}{|c|}{ Females } \\
\hline & DRR & (95\% C. I.) & DRR & (95\% C. I.) \\
\hline \multicolumn{5}{|l|}{ 1. Base model } \\
\hline Nicoya & 0.800 & $(0.69-0.93)$ & 0.978 & $(0.84-1.13)$ \\
\hline Year (2000 is 0$)$ & 0.991 & $(0.98-1.00)$ & 0.984 & $(0.98-0.99)$ \\
\hline Age (Gamma exp.) & 1.092 & $(1.09-1.10)$ & 1.101 & $(1.10-1.11)$ \\
\hline Constant $(\mathrm{m} 60$ per 1,000$))$ & 10.09 & $(9.27-10.98)$ & 6.66 & $(6.06-7.31)$ \\
\hline \multicolumn{5}{|l|}{ 2. SES controls model } \\
\hline Nicoya & 0.814 & $(0.70-0.95)$ & 0.941 & $(0.81-1.09)$ \\
\hline Education (years approved) & 1.010 & $(1.00-1.02)$ & 0.984 & $(0.97-0.99)$ \\
\hline \multicolumn{5}{|l|}{ Public health insurance } \\
\hline Paid (job/dependant) & 1 & Reference & 1 & Reference \\
\hline None & 0.938 & $(0.83-1.06)$ & 0.945 & $(0.83-1.08)$ \\
\hline Paid by government & 1.007 & $(0.92-1.11)$ & 1.075 & $(0.98-1.18)$ \\
\hline Year $(2000$ is 0$)$ & 0.990 & $(0.98-1.00)$ & 0.984 & $(0.98-0.99)$ \\
\hline Age (Gamma exp.) & 1.093 & $(1.09-1.10)$ & 1.101 & $(1.10-1.10)$ \\
\hline Constant (m60 per 1,000)) & 9.67 & $(8.71-10.74)$ & 7.14 & $(6.41-7.96)$ \\
\hline \multicolumn{5}{|l|}{ 3. Nicoya migrants model } \\
\hline Other Costa Rican & 1 & Reference & 1 & Reference \\
\hline Nicoya native resident & 0.775 & $(0.65-0.92)$ & 0.995 & $(0.85-1.17)$ \\
\hline Immigrant to Nicoya & 0.928 & $(0.67-1.30)$ & 0.845 & $(0.57-1.24)$ \\
\hline Nicoya out-migrant & 1.056 & $(0.85-1.32)$ & 0.818 & $(0.65-1.02)$ \\
\hline Year $(2000$ is 0$)$ & 0.991 & $(0.98-1.00)$ & 0.984 & $(0.98-0.99)$ \\
\hline Age (Gamma exp.) & 1.092 & $(1.09-1.10)$ & 1.102 & $(1.10-1.11)$ \\
\hline Constant $(\mathrm{m} 60$ per 1,000$))$ & 10.06 & $(9.25-10.96)$ & 6.70 & $(6.10-7.35)$ \\
\hline No. of subjects & 7,989 & & 8,326 & \\
\hline No. of failures & 2,902 & & 2,787 & \\
\hline Time at risk & 59,415 & & 63,833 & \\
\hline
\end{tabular}

of 0.93; similarly, the out-migrants (born in Nicoya but currently residing in other regions) have a non-significant DRR of 1.06 (Table 1). If migration patterns were unrelated to other mortality determinants, these latter results would be consistent with the hypothesis that the advantage of Nicoyan males results mostly from environmental conditions of the peninsula: men who leave Nicoya experience mortality rates rising to the level of all other Costa Ricans. However, it would be premature to embrace that conclusion since in this analysis we do not know the age of migration (i.e. degree of exposure to other environments), nor any health conditions leading to migration and other factors associated with differential migration selectivity. Thus we simply 
highlight the above associations so as to inform future research on genetic versus environmental determinants of the Nicoya advantage.

Nicoya effects estimated by the hazard regression models in Table 2 are not sensitive to the assumption of a Gompertz distribution. For example, Cox-regression models, which assume no functional form for the baseline hazard, result in a Nicoya effect of 0.796 DRR for males and 0.992 for females, compared to 0.800 and 0.978 from the base model in Table 2 .

The advantage of estimating Gompertz parameters is that it allows simple translation of results into more intuitive metrics, such as the probability that a 60 year old will become centenarian or his or her median remaining life. Table 3 shows these indicators for Nicoya as derived from the base model in Table 2 and compares them with contemporary estimates derived from the official life tables of two other longevity islands-Sardinia and the Okinawa Prefecture. To provide a larger context, Table 3 also compares with estimates of contemporary age specific mortality rates from Japan (the country with highest life expectancy in the world), the United States, Sweden and Costa Rica. All the indicators in the table are derived from the two parameters - alpha and gamma — of the Gompertz function estimated for Nicoya in Table 2, and for series of age-specific mortality rates in the other populations between ages 60 and 100 years as shown in the Appendix. The correlation coefficients between observed and Gompertz-fitted rates were higher than 0.995 in all cases.

The period probability of becoming a centenarian for a 60 -year-old man residing in Nicoya is $4.8 \%$ according to our 1990-2011 sample data. This probability is four times that of Costa Rican males, more than double that of Okinawa, the second highest in the comparison, and it is almost seven times that of Sardinia and Japan $(0.7 \%)$. Nicoya women have a slightly lower probability of becoming centenarian (4.3\%) than men, and this probability is less than half the exceptionally high figure of $9.3 \%$ of women in Okinawa. These metrics may be the most dramatic way of presenting the Nicoya advantage found in this dataset.

In terms of life expectancy and median lifetime, 60-year-old males in Nicoya (24.3 years) have almost a two-year advantage over Okinawans (22.6) and about a three-year advantage over Japanese and other Costa Rican men. Life expectancy at age 60 of Nicoya men is close to 24 years. According to the United Nations estimates, no country in the world had reached 24 years of male life expectancy at age 60 in 2012 (UN Population Division 2012). Nicoyan women are not as exceptional as their male counterparts; their median life time (25.1 years) and life expectancy (24.2 years) are more than four years shorter than the exceptional figures of about 29 years of women in Okinawa.

Since Nicoya estimates come from a sample of relatively few observations, it is important to also look at the confidence intervals included in Table 3. Even the lower bound of the intervals for Nicoya males is higher than the point estimates for the other populations, for example, a $2.9 \%$ probability of becoming centenarian compared to $2.1 \%$ of male Okinawans.

Causes of death might provide clues about factors behind the Nicoya advantage in elderly mortality. Unfortunately, the sample size of this study does not have enough 
Table 3:

Elderly survival indicators from the Gompertz model. Nicoya and other populations, periods centred by year 2000

\begin{tabular}{|c|c|c|c|c|c|}
\hline \multirow[b]{2}{*}{$\begin{array}{l}\text { Sex and } \\
\text { population }\end{array}$} & \multicolumn{2}{|c|}{ Gompertz parameters } & \multicolumn{3}{|c|}{ Survival for a 60 year old } \\
\hline & $\begin{array}{c}\alpha h(60) \\
\text { per } \\
1000\end{array}$ & $\begin{array}{c}\gamma \\
\text { Senescence } \\
\text { rate } \%\end{array}$ & $\begin{array}{c}\text { Becoming } \\
\text { centenarian } \\
\%\end{array}$ & $\begin{array}{l}\text { Median } \\
\text { life time } \\
\text { (years) }\end{array}$ & $\begin{array}{c}\text { Life } \\
\text { expectancy } \\
\text { (years) }\end{array}$ \\
\hline \multicolumn{6}{|l|}{ Males } \\
\hline Nicoya 2000 & 8.1 & $8.8 \%$ & $4.8 \%$ & 24.3 & 23.6 \\
\hline$(95 \% \mathrm{CI})$ & $(7.0-9.3)$ & $(8.5-9.1)$ & $(2.9-7.5)$ & $(23.0-25.8)$ & $(22.5-25.2)$ \\
\hline Sardinia 1995-2005 & 10.4 & $9.6 \%$ & $0.7 \%$ & 20.9 & 20.7 \\
\hline Okinawa 2000 & 9.1 & $9.2 \%$ & $2.1 \%$ & 22.6 & 22.4 \\
\hline Costa Rica 1995-2005 & 10.5 & $9.2 \%$ & $1.2 \%$ & 21.2 & 21.1 \\
\hline Japan 1995-2004 & 8.9 & $10.1 \%$ & $0.7 \%$ & 21.6 & 21.4 \\
\hline USA 1995-2004 & 12.2 & $9.3 \%$ & $0.5 \%$ & 19.7 & 19.7 \\
\hline Sweden 1995-2004 & 8.8 & $10.8 \%$ & $0.2 \%$ & 20.8 & 20.5 \\
\hline \multicolumn{6}{|l|}{ Females } \\
\hline Nicoya 2000 & 6.5 & $9.7 \%$ & $4.3 \%$ & 25.1 & 24.2 \\
\hline$(95 \% \mathrm{CI})$ & $(5.7-7.5)$ & $(9.4-10.0)$ & $(2.5-6.8)$ & $(23.7-26.5)$ & $(23.3-25.5)$ \\
\hline Sardinia 1995-2005 & 3.6 & $12.5 \%$ & $1.4 \%$ & 25.7 & 25.1 \\
\hline Okinawa 2000 & 3.0 & $11.3 \%$ & $9.3 \%$ & 29.3 & 28.5 \\
\hline Costa Rica 1995-2005 & 6.5 & $10.3 \%$ & $2.3 \%$ & 24.1 & 23.7 \\
\hline Japan 1995-2004 & 3.2 & $12.1 \%$ & $3.7 \%$ & 27.4 & 26.7 \\
\hline USA 1995-2004 & 6.9 & $10.2 \%$ & $1.8 \%$ & 23.6 & 23.2 \\
\hline Sweden 1995-2004 & 4.4 & $12.1 \%$ & $1.1 \%$ & 24.9 & 24.3 \\
\hline
\end{tabular}

Note: The Gompertz function death hazard $h$ at age $x$ is: $h(x)=\alpha \exp (\gamma x), x=$ age-60 years. The Appendix gives the observed and predicted values and provides information about the Gompertz fit.

$\mathrm{CI}=95 \%$ confidence intervals estimated with Monte Carlo simulation of 1,000 values of $\gamma$ and the $\log$ of $\alpha$, assuming they are normally distributed with standard deviations estimated by the hazard regression base model in Table 2.

statistical power to conduct a detailed analysis by cause of death. It is feasible to analyse just the two largest groups of causes of death: cardiovascular diseases and cancer. The Nicoya subsample contains 123 cardio-vascular and 70 cancer deaths. The hazard regression models implicate mortality by cardio-vascular diseases in men as the main and only origin of the Nicoya advantage (Figure 3). The corresponding DRR is 0.65 (95\% CI: $0.50-0.86$ ). Mortality by cancer is essentially the same in Nicoya as in the rest of Costa Rica, as is female cardiovascular disease mortality.

\subsection{Census survival ratio}

A confirmation that Nicoyans have a survival advantage, which is independent of the registry of deaths, comes from survival ratios computed between censuses (Table 4). 


\section{Figure 3:}

Death rate ratio (DRR) of elderly Nicoyans compared to other Costa Ricans. All causes, cardiovascular disease (CVD) and cancer mortality 1990-2011
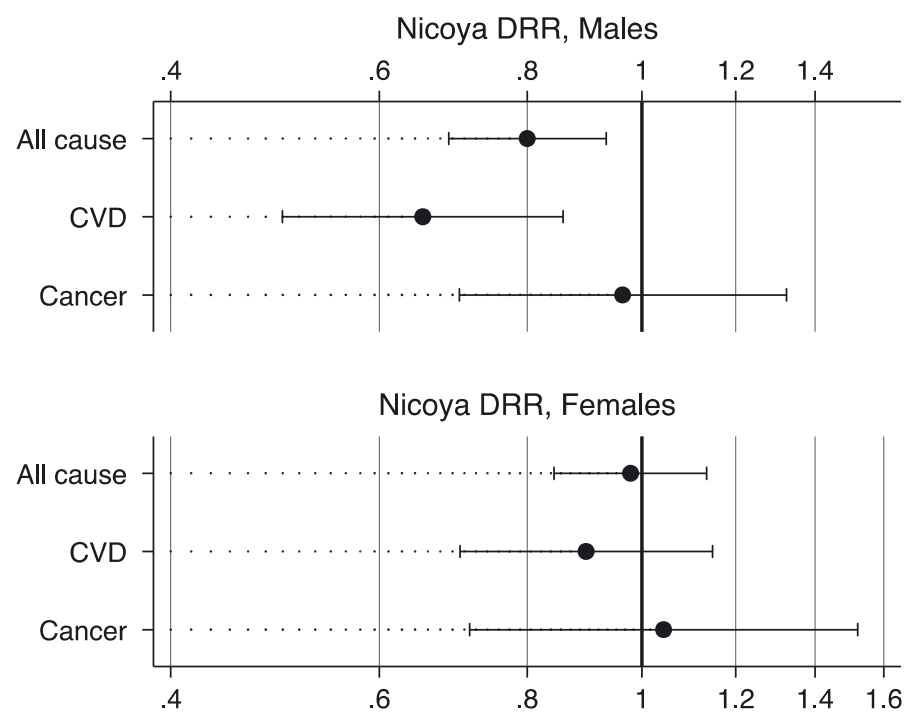

The survival ratio of people aged 60 or more in the 1984 census to the 2000 census (in which they are $76+$ years) is $15 \%$ higher for men born in Nicoya than for those born in the rest of Costa Rica and 6\% higher for women. The corresponding ratios for the period of 27 years between the 1984 and 2011 censuses are 32\% higher survival for Nicoya men and $21 \%$ for Nicoya women. It is important to note that these estimates are free of internal migration bias since the group of Nicoyans was defined by place of birth rather than place of residence.

Census data on the sex ratio at very old ages are, in turn, consistent with the finding that the mortality advantage of Nicoya occurs only among men. According to the 2011 census the sex ratio (female to males) of people in Nicoya aged 90 years or more is just 1.2 , compared to the 1.5 ratio of Costa Rica, or the substantially higher ratios of 3.0 in Japan, 3.1 in the USA and 3.5 in France, among other high-income countries (Rosero-Bixby 2008). The excess mortality of males has to be substantially small in Costa Rica and, especially in Nicoya, to produce these sex ratios close to one among the oldest old survivors.

\subsection{Biomarkers and health risk factors}

CRELES data on biomarkers for about 600 observations in Nicoya and 4,500 in the rest of Costa Rica are consistent with the mortality results: the Nicoya advantage 
Table 4:

Inter-census cohort survival ratios

\begin{tabular}{lrrrrr}
\hline & \multicolumn{2}{c}{ Survival ratio } & & \multicolumn{2}{c}{ N denominator } \\
Birth place & Males & Females & & Males & Females \\
\hline 1984-2000 survival, $N(76+) / N(60+)$ & & & & \\
$\quad$ Nicoya native & 0.499 & 0.521 & & 4,782 & 4,999 \\
$\quad$ Other Costa Rica & 0.434 & 0.492 & & 65,325 & 70,988 \\
$\quad$ Ratio Nicoya/other CR & $\mathbf{1 . 1 5 0}$ & $\mathbf{1 . 0 5 8}$ & & \\
\hline 2000-2011 survival, $N(87+) / N(76+)$ & & & & \\
$\quad$ Nicoya native & 0.311 & 0.382 & 2,387 & 2,602 \\
$\quad$ Other Costa Rica & 0.271 & 0.334 & 28,362 & 34,929 \\
$\quad$ Ratio Nicoya/other CR & $\mathbf{1 . 1 4 5}$ & $\mathbf{1 . 1 4 3}$ & & \\
\hline 1984-2011 survival, $N(87+) / N(60+)$ & & & & \\
$\quad$ Nicoya native & 0.155 & 0.199 & & 4,782 & 4,999 \\
$\quad$ Other Costa Rica & 0.118 & 0.164 & 65,325 & 70,988 \\
$\quad$ Ratio Nicoya/other CR & $\mathbf{1 . 3 1 6}$ & $\mathbf{1 . 2 0 9}$ & & \\
\hline
\end{tabular}

Source: Census micro-databases online: http://ccp.ucr.ac.cr/censos/

shows up mostly in cardiovascular risk markers and tends to concentrate in males. Figure 4 shows the difference between Nicoya and the rest of the country in the normalised biomarker level as estimated with regressions that control confounding effects of age, as well as gender when the estimate is for both sexes together. (The figure shows estimates by sex only for biomarkers in which preliminary analyses showed significant sex-Nicoya interaction effects.) Negative values indicate that Nicoya residents have a lower marker level, measured in standard deviations.

Nicoya residents show significantly lower levels in the following markers of cardiovascular risk: triglycerides, fasting glucose and $\mathrm{HbA} 1 \mathrm{c}$ for males and cholesterol, waist circumference, BMI and (marginally) diastolic blood pressure for both sexes together.

Biomarkers in Figure 4 also show that elderly people in Nicoya, both males and females, have lower levels of functional disabilities and cognitive deterioration; i.e. they seem to have a healthier ageing process. They may also have lower levels of stress if we take their significantly longer telomeres and significantly higher levels of DHEAS as markers of stress. Since these two biomarkers are also closely associated to ageing, the longer telomeres and higher DHEAS level in Nicoya suggest a slower ageing process in this population.

Elderly Nicoyans are also significantly taller than other Costa Ricans as measured by knee height. This result suggests that Nicoyans had healthier growth and development in childhood - and possibly even in-utero - as a result of better diet and fewer infections. However, we cannot yet distinguish this hypothesis from the possibility of a more severe survival selection of the fittest in Nicoya. 
Figure 4:

Nicoya effect in selected biomarkers in the CRELES sample

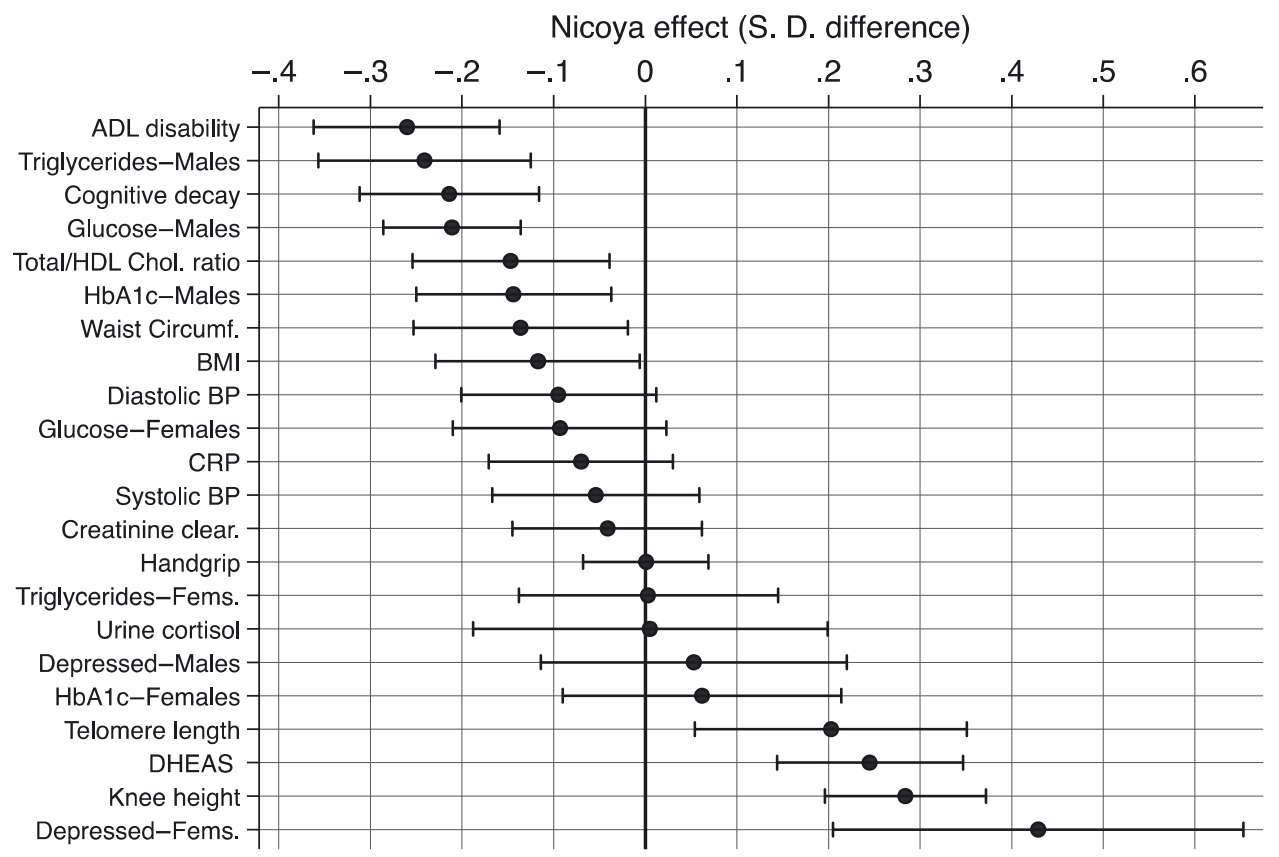

Note: The effects were estimated with OLS regressions on the normalised biomarkers controlling for age and sex with CRELES databases for waves 1 and 2.

The lack of significant differences in the CRP marker might reflect countervailing influences. Better cardiovascular health would lower CRP, but barriers to proper sanitation infrastructure in this mostly rural region could cause any CRP advantage to be offset by a greater infectious disease burden.

An intriguing result that merits further research is the higher prevalence of geriatric depression in Nicoya females. Why does this strong negative condition of Nicoya occur only among females? In this paper we can only highlight the finding, leaving more detailed investigation for future work.

Moving beyond biomarkers, Table 5 shows health risk factors and behaviours that could help us to further understand the Nicoya advantage. The table shows that smoking levels are not different in Nicoya. Physical activity is higher in elderly Nicoyans (30\% vs. 27\%), although this difference is small and not statistically significant-possibly because of the crude way CRELES measured the variable with a yes/no question. ${ }^{4}$

4 Question EV14: In the last 12 months, have you exercised regularly or done other physically rigorous activities like sports, jogging, dancing or heavy work, three times a week? 
Table 5:

Health risk factors

\begin{tabular}{lcccc}
\hline Health factors & Nicoya & Other Costa Rica & Odds ratio & (95\% CI) \\
\hline Smoker currently & 0.36 & 0.36 & 0.99 & $(0.94-1.05)$ \\
Smoker past & 0.21 & 0.21 & 0.99 & $(0.83-1.18)$ \\
Physically active & 0.30 & 0.27 & 1.18 & $(0.94-1.48)$ \\
Visited at home by health worker & 0.45 & 0.41 & 1.15 & $(0.97-1.38)$ \\
Received flu vaccine & 0.64 & 0.59 & $1.24^{*}$ & $(1.04-1.49)$ \\
High BP medicine & 0.46 & 0.51 & $0.82+$ & $(0.66-1.02)$ \\
Lipid lowering medicine & 0.14 & 0.27 & $0.43^{* *}$ & $(0.32-0.59)$ \\
Diabetes medicine & 0.18 & 0.20 & 0.87 & $(0.62-1.21)$ \\
Conditional on being sick: & & & & \\
$\quad$ High BP medicine & 0.63 & 0.67 & 0.86 & $(0.68-1.09)$ \\
$\quad$ Lipid lowering medicine & 0.29 & 0.36 & $0.71+$ & $(0.48-1.04)$ \\
$\quad$ Diabetes medicine & 0.53 & 0.55 & 0.92 & $(0.62-1.36)$ \\
\hline
\end{tabular}

** significant at $\mathrm{P}<.01,{ }^{*}$ significant at $\mathrm{P}<.05,+$ significant at $\mathrm{P}<.10$

Approximate N: 7,200 observations in the three CRELES waves, including 870 from Nicoya.

The proportions are predicted probabilities for samples with mean age 72 years and sex ratio of one, which were obtained using logistic regressions.

Two indicators of preventive health services-household visit by a health worker and flu vaccination within the past year-suggest elderly Nicoyans are better served by the Costa Rican primary healthcare system. While $64 \%$ of Nicoyans were vaccinated, only $59 \%$ of other Costa Ricans were. Moreover, Nicoyans consume less of the three most common drugs for chronic conditions in contemporary medicine: blood pressure and blood lipid lowering pills and diabetes medication. This result in part mirrors the lower prevalence of these conditions in Nicoya, but it also shows lower consumption when individuals are sick. Lipid-lowering medicine is the clearest example: $14 \%$ of Nicoyans take it compared to $27 \%$ of other Costa Ricans. When only individuals with high levels of total cholesterol are considered, the proportion taking the medicine is $29 \%$ and $36 \%$, respectively. Thus preventive health services analysed here provide a mixed picture of Nicoyan advantages and deficits.

\subsection{Dietary macronutrients}

The data on frequency of food consumption in CRELES showed some significant but small differences in the diet of elderly Nicoyans compared to other Costa Ricans. Nicoya diets include significantly more plain, quotidian foods like rice, beans, beef, fish, chicken, light cheese and sodas; and significantly less of 'fancy' foods like aged cheese, olive oil or mayonnaise, less salad ingredients (lettuce, avocado, carrot, tomato) and less processed and fast foods such as white bread, cookies and hamburgers. They also drink significantly less milk (an average 0.5 glass 


\section{Figure 5:}

Nicoya effect in selected dietary macronutrients in the CRELES sample

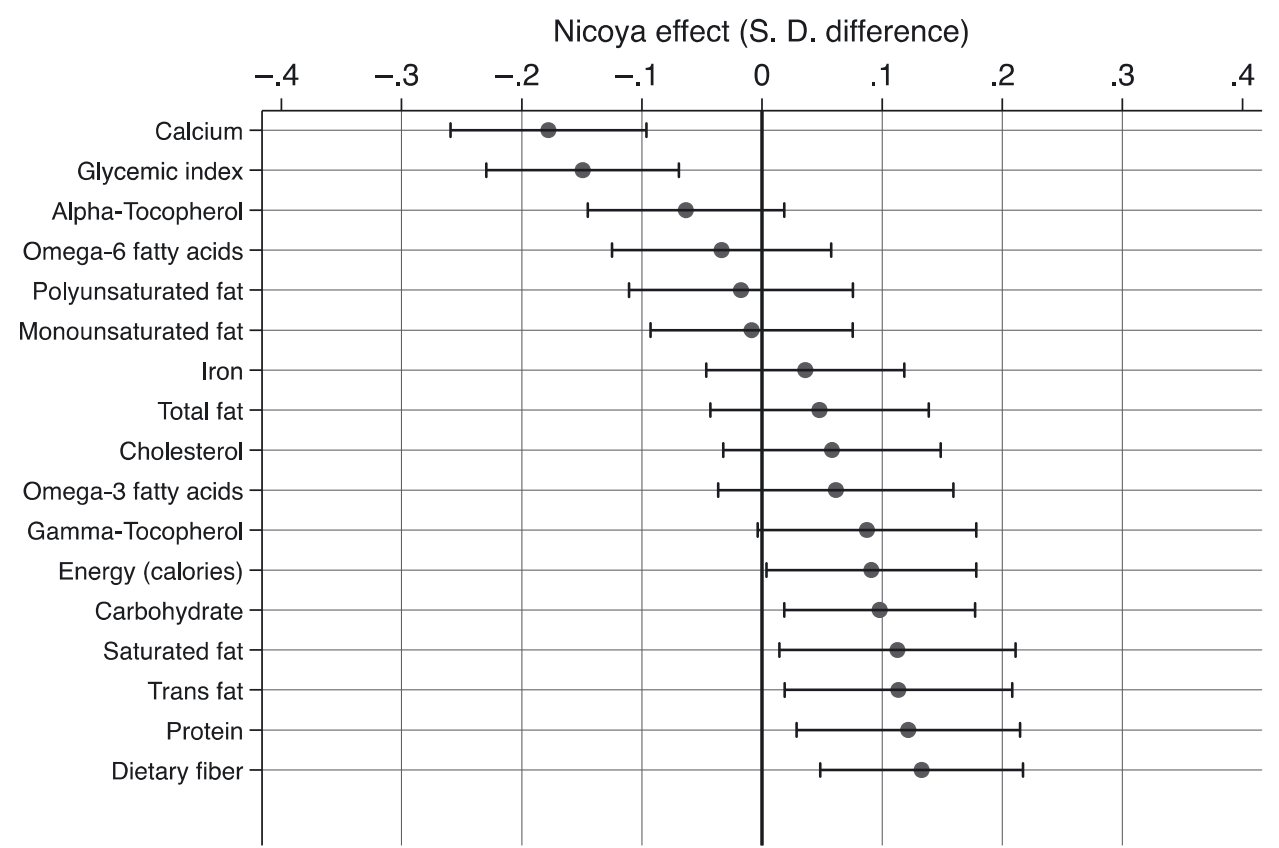

Note: The effects were estimated with OLS regressions on the normalised macronutrients controlling for age, sex and interaction of health worker and wave. CRELES databases for waves 1,2 and 3 .

per day compared to 0.7 glass by other Costa Ricans). There are no differences in consumption of fresh fruits, eggs, sugar, pastries and potato chips.

These dietary patterns translate into the macronutrient differences of Figure 5. The figure shows the Nicoya effect in normalised metrics; i.e. measured in standard deviations. Negative figures indicate that consumption in Nicoya is lower than in the rest of Costa Rica.

Nicoyans eat or drink more calories, carbohydrates, proteins (mostly of animal origin) and fibre. Although they do not differ in the consumption of total fat, their significantly higher levels of saturated and trans fats probably come from the use of cheaper brands of oils. Calcium and the glycemic index are the only two macronutrients in Figure 5 with significantly lower consumption in Nicoya. However, the estimated differences in macronutrients are small: no larger than 0.2 standard deviations. For example, Nicoyans consume $3 \mathrm{~g} / \mathrm{d}$ more protein than the $70 \mathrm{~g} / \mathrm{d}$ Costa Rican average; their glycemic index is one point lower than the 76-point national average (an index of 100 corresponds to pure sugar); or their intake of fibre is one $\mathrm{g} / \mathrm{d}$ higher than the national average of $23 \mathrm{~g} / \mathrm{d}$. 
Both the lower glycemic index and the higher dietary fibre consumption in Nicoya's diet indicate a lower consumption of processed or refined foods, and a greater adherence to traditional foods such as rice, beans and animal proteins. The lower intake of calcium mirrors the low consumption of cow milk by Nicoyans but also reflects the fact that other sources of calcium were not included in the estimate.

\section{Discussion}

Spatial analysis in quasi-extinct cohorts of Costa Ricans identifies a cluster of lower mortality rates in the Nicoya region with a 0.83 death rate ratio (DRR) compared to the national average. A survival follow-up in a sample of 16,300 elderly Costa Ricans estimated the Nicoya DRR to be 0.80 (0.69-0.93 CI) for males 1990-2011. Compared to the Japanese, the probability of becoming a centenarian for a 60year-old Nicoya male is almost seven-times higher and his life expectancy is 2.1 years longer. This Nicoya advantage does not occur in females, is independent of socio-economic conditions, disappears in out-migrants, and can be statistically explained by lower cardiovascular mortality $(D R R=0.65)$. Nicoyans have lower levels of markers of cardiovascular risk; they are also leaner, taller and have fewer disabilities (physical and mental). Two markers of ageing and stress-telomere length and DHEAS - are more favourable in Nicoya. The prosaic Nicoya diet is more abundant in traditional foods like rice, beans and animal protein with a lower glycemic index and higher fibre content. They also drink significantly less milk than other Costa Ricans. Curiously, they have a substantially lower probability of taking blood pressure and blood lipid lowering medicines, even among those at clinical risk. But otherwise, elderly Nicoyans do show higher utilisation of basic, preventive public healthcare services.

While the findings presented here are descriptive, the mortality estimates and other supporting data in this article provide compelling evidence that Nicoya is indeed one of the rare high-longevity hot spots that scientists have searched for in the hope of providing hints about the determinants of healthy ageing. The two- or three-year advantage in life expectancy among elderly male Nicoyans-compared to not only other Costa Ricans but also to Japanese males-is a striking achievement, particularly considering that they live in a less developed region of a middle-income country where health expenditures are one-tenth of those in rich countries and thus with limited access to high-tech, specialised medicine.

There are no clear-cut criteria to define a place as a longevity island. Only little comparable statistical information is available from other sub-populations with the reputation of being longevity islands or 'blue zones' to draw definite conclusions about whether Nicoya should be included in this classification. The "centenarian rate" (Robine and Paccaud 2005) often computed with cohort census data to identify long-living populations is not a reliable estimator for Nicoya and other places with small population size. We have used here an analogous indicator to assess longevity: the period probability of becoming a centenarian for a 60 -year-old individual, which 
we have estimated as 4.8\% for males and 4.3\% for females in Nicoya 1990-2011. Data for national populations centred in the year 2000 from the Human Mortality Database show that this probability among males is, for example, $0.7 \%$ in Japan, $0.5 \%$ in the United States and $0.2 \%$ in Sweden: several times smaller than in Nicoya. In two other longevity islands this probability is also substantially lower: $2.1 \%$ in Okinawa and $0.7 \%$ in Sardinia. For females, this probability is $3.7 \%, 1.8 \%$ and $1.1 \%$ in those three countries, respectively, and 9.3\% in Okinawa and 1.4\% in Sardinia. Since this indicator is increasing over time, the reference period is important. For example, in Sweden 100 years earlier, in 1900-1909, the probability was one-tenth smaller: $0.03 \%$ in males and $0.09 \%$ in females (HMD 2012).

This article's estimates of exceptionally high longevity in the Nicoya region are unlikely to be an artifact of data errors, or more specifically, of age exaggeration. Ages in the quasi-extinct cohort database, in the survival follow-up sample, and in the CRELES data were not taken from self-reports but come from exact computation using the date of birth as recorded in the Costa Rican Birth Registry and excluding late registrations and naturalisations. Moreover, since the high-longevity evidence comes from comparing Nicoyans to other Costa Ricans, the bad-data hypothesis should be exclusive of (or more prevalent among) people from Nicoya and only among males with cardiovascular disease. If it were due to some identity forgery or impersonation in the birth registration system (an unlikely hypothesis), it would have to be concentrated in Nicoya and in males only, which we have no reason to believe has occurred.

Another indication of the validity of the estimates is the observed coherence between different data sources and health indicators. Census data confirm that elderly Nicoya natives, especially males, have a clear cohort survival advantage. In turn, the close-to-one census sex ratio in oldest old Nicoyans suggests that the mortality gender gap observed in other populations is smaller or nonexistent in Nicoya thanks to an exceptionally low mortality of males. Biomarkers measured in the CRELES survey show that Nicoyans have better indicators of cardiovascular and metabolic risk, a result that is coherent with that of lower cardiovascular mortality. CRELES data also suggest that a slower ageing process occurs in Nicoya elders given their longer telomeres, higher DHEAS levels and fewer physical and mental disabilities.

The limited available information on frequency of food consumption suggests a prosaic Nicoya diet that does not fit clearly into any of the popular theories about diets conducive to living long, such us the Mediterranean diet (Willett 2001), the calorie-restriction diet (Walford and Walford 2005), the Okinawan diet (Hiroko 2001) or the low animal protein diet (Campbell and Campbell II 2005). The data do not show that Nicoyans eat more of reputedly healthy foods like salads, fruits, olive oil or nuts, nor that they eat less fat, animal protein and sugars among other foods associated with worse health. Compared to other Costa Ricans, they take up slightly but significantly more calories, proteins and carbohydrates (although with higher fibre content and lower glycemic index) as part of a plain diet that includes rice, beans, fish, beef and chicken. However, the association of a lower glycemic index diet in Nicoya is consistent with the most recent nutritional evidence suggesting the 
primary importance of this as a determinant of cardiovascular health (Jenkins et al. 2002).

A distinctive characteristic of the Nicoya diet is the low consumption of cow's milk, which according to some literature is a healthy behaviour to avoid autoimmuneresponse diseases like diabetes (Campbell and Campbell II 2005). Because of this pattern we estimate significantly lower levels of calcium in the Nicoya diet. However, this result may be down-biased by not including in the estimating equation the high consumption of corn tortillas prepared with nixquezado maize in the Chorotega culture, which is a method to cook the kernels with lime that adds high concentration of calcium, as well as the high contents of calcium and magnesium in drinking water of the region (Buettner 2010), which were not accounted for in our estimate either.

The finding that out-migrants from Nicoya may have lost their survival advantage hints at the importance of the environment, relative to genetics. This is an important clue for further research, although it must be considered cautiously, owing to the complexities of selection biases that often accompany migration processes.

A limitation in our survival analyses was to take Nicoya residence as a time-fixed variable at the beginning of the observation period. However, the likely bias of not excluding out-migration would actually lead this to be an under-estimation of the Nicoya effect. Another limitation in the analyses was the lack of statistical power to detect some effects or to disaggregate the analysis because of the small sample size of the Nicoya component in the samples, although this does not limit our overall findings of the Nicoya old-age survival advantage. An important cautionary note is about over-interpreting the peculiarities of Nicoya residents in diet, biomarkers or other characteristics as proof of their causal role in explaining the Nicoya survival advantage. Much more research is needed to establish such causal links.

It may well be that further spatial analyses to detect clusters of low elderly mortality within other low-mortality countries will yield compelling evidence of many more such hot spots, which would substantially enhance the possibility of creative research designs to better test the causal determinants of Nicoyan-like outstanding longevity.

\section{Acknowledgements}

Data collection and data processing for this study were conducted in the Central American Population Center (CCP) of the University of Costa Rica. The Costa Rican Institute of Statistics and Census (INEC) provided the samples for the longitudinal mortality studies. The Costa Rican Tribunal Supremo de Elecciones provided the micro databases of births, deaths and voting registry for the extinct cohort analysis and the mortality follow-ups. The CRELES panel is a research project of the University of Costa Rica. Grants from Florida Ice and Farm Co., Wellcome Trust (072406/Z/03/Z) and the National Institute of Aging (P30AG012839 and R01AG031716) funded parts of the study. 


\section{Appendix: The Gompertz fit}

The 'Gompertz law' states that mortality increases exponentially with age (Gompertz 1825). Neither its creator nor the many scholars who have used it assume that this law applies to the entire lifespan of humans (Carnes et al. 1996). It is simply a convenient tool that well describes adult and elderly mortality until high ages at which a deceleration takes place (Horiuchi and Wilmoth 1998). Although other complex models, with as much as eight or more parameters, capture that deceleration (Lynch and Brown 2001), the two-parameter Gompertz model is by far the most convenient formulation with overall variance explained (R2) near $99 \%$ after age 30 years (Bongaarts and Feeney 2002).

Old-age mortality deceleration usually starts after age 95 years in developed countries. Lynch and Brown (2001) found that in the United States this age is increasing, reaching 96.6 years in 1992. It is thus likely that more recent data, or data from populations with lower mortality, would show deceleration beginning close to 100 years of age. Moreover, recent estimates with high quality data have questioned the deceleration paradigm and suggested that it might be appropriate to continue using Gompertz beyond age 100 (Gavrilov and Gavrilova 2011).

To contextualise Nicoya estimates, we used Gompertz to describe and fit agespecific mortality rates in ages 60 to 100 years in six populations and periods centred in the year 2000 as shown in Figure A.1. We used the following data sources:

- Costa Rica: observed age-specific mortality rates in 1995-2000 and 2000-2005, estimated by the Central American Population Center (CCP 2012a).

- Okinawa: the age-specific mortality rates reported in the official life table for the Okinawa Prefecture in year 2000 prepared by the Japanese Ministry of Health Labour and Welfare (2003)

- Sardinia: average of the age-specific mortality rates in the annual life tables for the Autonomous Region of Sardinia 1995-2005 produced by the Italian National Institute of Statistics (2013)

- Japan, Sweden and United States, average mortality rates in the periods 1995-99 and 2000-04 reported in the Human Mortality Database (HMD 2012).

We estimated for each sex the two-parameter Gompertz model for the death hazard $h$, or mortality rate, at age $x$ :

$$
h_{x}=\alpha \cdot e^{\gamma \cdot x} ; \quad x=\text { age }-60 \text { and } \quad 60 \leq \text { age }<100 \text { years },
$$

where the constant $\alpha$ measures the mortality rate at $x=0$, or age 60 , and $\gamma$ is the senescence rate (the proportional increase in mortality per year of age).

The correlation coefficients between Gompertz-predicted and observed hazards were higher than 0.995 in all of the twelve fitted models. With the two Gompertz parameters it is possible to determine a battery of more intuitive indicators of mortality, survival and expected life (Pollard 1991). We estimated two of them: 
Figure A.1:

Gompertz fit of age-specific mortality rates by sex in selected populations circa 2000
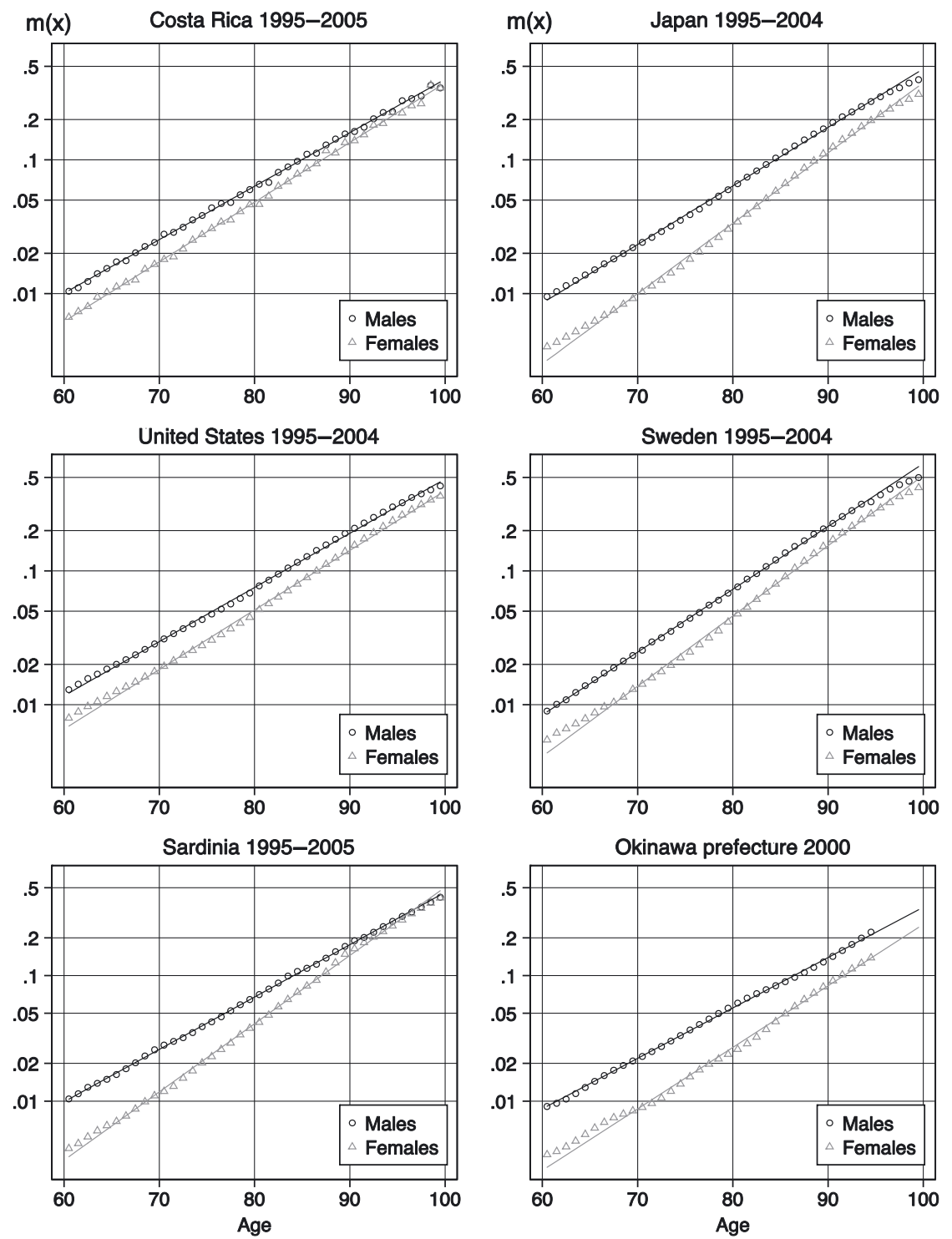

1. The proportion of survivors $S$ at age 100, or the probability of becoming a centenarian for an individual who just reached age 60:

$$
S_{x}=e^{(\alpha / \gamma) \cdot\left(1-e^{\gamma x}\right)} \quad \text { for } \quad x=40 \quad \text { (i.e. age 100) }
$$


2. The median lifetime $M L$, or the time when $50 \%$ of the 60 -year-old cohort has died, i.e. when $S_{x}=0.5$ :

$$
M L=(1 / \gamma) \cdot \ln [1+(\gamma / \alpha) \cdot \ln (2)]
$$

We also determined life expectancy at age 60. However, since there is not a simple formula to obtain it, we estimated it by numerical integration of the survival function. Life expectancy may be, however, biased since to compute it we are extrapolating the Gompertz function beyond 100 years of age.

\section{References}

Bongaarts, J., and G. Feeney. 2002. "How Long Do We Live?" Population and Development Review 28 (1): 13-29. doi:10.1111/j . 1728-4457.2002 .00013. $\mathrm{x}$.

Buettner, D. 2010. The Blue Zones: Lessons for Living Longer From the People Who've Lived the Longest. Washington, D.C.: National Geographic.

Campbell, T. C., and T. M. Campbell. 2005. The China Study: The Most Comprehensive Study of Nutrition Ever Conducted and the Startling Implications for Diet, Weight Loss and Long-Term Health. Dallas, Tex.: BenBella Books.

Carnes, B. A., S. J. Olshansky, and D. Grahn. 1996. "Continuing the Search for a Law of Mortality". Population and Development Review 22 (2): 231-264. doi:10. $2307 / 2137434$.

Caselli, G., and R. M. Lipsi. 2006. "Survival Differences Among the Oldest Old in Sardinia: Who, What, Where, and Why?" Demographic Research 14 (13): 267-294. doi:10.4054/DemRes. 2006.14.13.

CCP. 2012. Indicadores demográficos Costa Rica: Tablas de vida completas quinquenales. Tech. rep. Centro Centroamericano de Población, Universidad de Costa Rica. http : / / ccp . ucr . ac . cr / observa / CRindicadores / TVcompletas.html.

Coale, A. J., and E. E. Kisker. 1986. "Mortality Crossovers: Reality or Bad Data?" Population Studies 40 (3): 389-401. doi:10. 1080/0032472031000142316.

Garson, L. K. 1991. "The Centenarian Question: Old-Age Mortality in the Soviet Union, 1897 to 1970". Population Studies 45 (2): 265-278. doi:10 . 1080 / 0032472031000145436 .

Gavrilov, L. A., and N. S. Gavrilova. 2011. "Mortality Measurement at Advanced Ages: A Study of the Social Security Administration Death Master File". North American Actuarial Journal: 432-447.

Gompertz, B. 1825. "On the Nature of the Function Expressive of the Law of Human Mortality, and on a New Mode of Determining the Value of Life Contingencies". Philosophical Transactions of the Royal Society of London 115: 513-583. 
Halstead, S. B. 1985. Good Health at Low Cost: Proceedings of a Conference Held at the Bellagio Conference Center. Ed. by J. Walsh and K. S. Warren. New York: Rockefeller Foundation.

Hill, K., R. Pande, M. Mahy, and G. Jones. 1999. Trends in Child Mortality in the Developing World: 1960-1996. New York: UNICEF.

Hiroko, S. 2001. "History and Characteristics of Okinawan Longevity Food". Asia Pacific Journal of Clinical Nutrition 10 (2): 159-164.

HMD. 2012. Human Mortality Database. University of California, Berkeley (USA) and Max Planck Institute for Demographic Research (Germany). Retrieved November 2, 2012. http://www .mortality .org.

Horiuchi, S., and J. R. Wilmoth. 1998. "Deceleration in the Age Pattern of Mortality at Older Ages". Demography 35 (4): 391-412. doi:10.2307/3004009.

Hosmer, D. W., and S. Lemeshow. 1999. Applied Survival Analysis: Regression Modeling of Time to Event Data. New York: John Wiley \& Sons.

IMN. 2012. Datos climáticos. Retrieved May 15, 2013. http://www . imn. ac.cr/ \%20IMN/MainAdmin . aspx?EVENTTARGET=ClimaCiudad\&CIUDAD=5.

INEC and CCP. 2013. Estimaciones y proyecciones de población por sexo y edad 1950-2050. San Jose, Costa Rica: Instituto Nacional de Estadística y Censos.

Italian National Institute of Statistics. 2013. I.Stat-Direct Acces to Statistical Data/Population and Households/Mortality/Life Tables Data by Single Age Class. Retrieved May 2, 2013. http://dati . istat.it/?lang=en.

Jenkins, D., C. W. Kendall, L. S. Augustin, S. Franceschi, M. Hamidi, A. Marchie, A. L. Jenkins, and M. Axelsen. 2002. "Glycemic Index: Overview of Implications in Health and Disease". The American Journal of Clinical Nutrition 76 (1): 2665-2735.

Kulldorff, M. 1997. "A Spatial Scan Statistic”. Communications in Statistics: Theory and Methods 26 (6): 1481-1496. doi:10.1080/03610929708831995.

Leaf, A., and J. Launois. 1975. Youth in Old Age. New York; Toronto: McGraw-Hill.

Lynch, S. M., and J. S. Brown. 2001. "Reconsidering Mortality Compression and Deceleration: An Alternative Model of Mortality Rates". Demography 38 (1): 79-95. doi:10.1353/dem.2001.0007.

MHLW. 2003. Life Tables by Prefecture for 2000 [In Japanese]. Tokyo: Japanese Ministry of Health, Labour / Welfare.

Missov, T. I., and A. Lenart. 2011. "Linking Period and Cohort Life-Expectancy Linear Increases in Gompertz Proportional Hazards Models". Demographic Research 24 (19): 455-468. doi:10.4054/DemRes.2011.24.19.

Pittier, H. 2011. “Impresiones y recuerdos: José Silverio Gómez 1801-1904”. Ensayo del conservacionista Henri Pittier (1857-1950) realizado en 1904. Es posiblemente el primer testimonio sobre la excepcional longevidad de los habitantes de la Península de Nicoya, Costa Rica. Pandemonium 3 (45): 5-8, 3-7. 
Pollard, J. H. 1991. "Fun With Gompertz". Genus XLVII (1-2): 1-20.

Poulain, M. 2011. "Exceptional Longevity in Okinawa: A Plea for In-Depth Validation". Demographic Research 25 (7): 245-284. doi:10 . 4054 / DemRes . 2011.25.7.

Preston, S. H., I. T. Elo, and Q. Stewart. 1999. "Effects of Age Misreporting on Mortality Estimates at Older Ages". Population Studies 53 (2): 165-177. doi:10. $1080 / 00324720308075$.

Rehkopf, D. H., W. H. Dow, L. Rosero-Bixby, J. Lin, E. S. Epel, and E. H. Blackburn. 2013. "Longer Leukocyte Telomere Length in Costa Rica's Nicoya Peninsula: A Population-Based Study". Experimental Gerontology 48 (11): 1266-1273.

Robine, J.-M., and F. Paccaud. 2005. "Nonagenarians and Centenarians in Switzerland, 1860-2001: A Demographic Analysis". Journal of Epidemiology and Community Health 59 (1): 31-37. doi:10.1136/jech. 2003.018663.

Rosero-Bixby, L. 2008. "The Exceptionally High Life Expectancy of Costa Rican Nonagenarians". Demography 45 (3): 673-691.

Rosero-Bixby, L., and D. Antich. 2010. "Estudio Longitudinal De Mortalidad De Adultos Costarricenses 1984-2007”. Población Y Salud en Mesoamérica 7 (2).

Rosero-Bixby, L., and W. H. Dow. 2009. "Surprising SES Gradients in Mortality, Health, and Biomarkers in a Latin American Population of Adults". The Journals of Gerontology. Series B: Psychological Sciences and Social Sciences 64 (1): 105-117. doi:10.1093/geronb/gbn004.

Rosero-Bixby, L., and W. H. Dow. 2012. "Predicting Mortality With Biomarkers: A Population-Based Prospective Cohort Study for Elderly Costa Ricans". Population Health Metrics 10 (11): 1-15. doi:10.1186/1478-7954-10-11.

Rosero-Bixby, L., X. Fernández, and W. H. Dow. 2010. CRELES: Costa Rican Longevity and Healthy Aging Study, 2005 (Costa Rica Estudio De Longevidad $Y$ Envejecimiento Saludable) (ICPSR 26681). Ed. by National Archive of Compuetrized Data on Aging. http : //www . icpsr . umich . edu/icpsrweb / NACDA/studies/26681/documentation\%20doi : 10.3886/ICPSR26681.v2.

Schoenfeld, D. A. 1983. "Sample-Size Formula for the Proportional-Hazards Regression Model”. Biometrics 39 (2): 499-5033. doi:10.2307/2531021.

Thomas, A. J., and B. P. Carlin. 2003. "Late Detection of Breast and Colorectal Cancer in Minnesota Counties: An Application of Spatial Smoothing and Clustering". Statistics in Medicine 22 (1): 113-127. doi:10. 1002/sim. 1215.

Tosi, J. A. 1969. Mapa ecológico de Costa Rica. Ed. by T. S. Center. In collab. with J. Tosi. San José, Costa Rica.

UN Population Division. 2012. Population Ageing and Development 2012: Wall Chart. http : / / www . un . org / esa / population / publications / 2012PopAgeing\%20Dev\%20Chart/2012AgeingWallchart.html..

United Nations. 1961. Demographic Yearbook. New York: United Nations. 
Walford, R. L., and L. Walford. 2005. The Anti-Aging Plan: The Nutrient-Rich, Low-Calorie Way of Eating for a Longer Life-The Only Diet Scientifically Proven to Extend Your Health Years. Cambridge, MA: Da Capo Press.

Willcox, B. J., D. C. Willcox, and L. Ferrucci. 2008a. "Secrets of Healthy Aging and Longevity From Exceptional Survivors Around the Globe: Lessons From Octogenarians to Supercentenarians". The Journals of Gerontology. Series A, Biological Sciences and Medical Sciences 63 (11): 1181-1185.

Willcox, D. C., B. J. Willcox, Q. He, N.-c. Wang, and M. Suzuki. 2008b. "They Really Are That Old: A Validation Study of Centenarian Prevalence in Okinawa". The Journals of Gerontology. Series A: Biological Sciences and Medical Sciences 63 (4): 338-349.

Willett, W. C. 2001. Eat, Drink, and Be Healthy: The Harvard Medical School Guide to Healthy Eating. New York: Simon / Schuster.

World Bank. 2012. World Development Indicators. Retrieved January 17, 2013. http://databank . worldbank . org/data/home . aspx.

Young, R. D., B. Desjardins, K. McLaughlin, M. Poulain, and T. T. Perls. 2010. "Typologies of Extreme Longevity Myths". Current Gerontology and Geriatrics Research 2010 (423087). doi:10 . 1155/2010/423087. 